\title{
Homo Politicus Was Born This Way: How Understanding the Biology of Political Belief Promotes Depolarization
}

Alexander Severson, Boise State University *

${ }^{*}$ Direct all correspondence to Alexander W. Severson, Department of Political Science, Boise State University, Boise, ID $83703<$ alexseverson@boisestate.edu>. I will readily share all data and coding information with those researchers who wish to replicate the study. The authors are responsible for any errors of omission or commission as well as the interpretations and conclusions made in this paper. 


\begin{abstract}
Most individuals perceive ideological beliefs as being freely chosen. Recent research in genopolitics and neuroscience, however, suggests that this conviction is partially unwarranted given that biological and genetic factors explain more variance in political attitudes than choice and environmental factors. Thus, it is worth exploring whether exposure to this research on the biological and genetic basis of political attitudes might influence levels of affective polarization because such exposure might reduce the perceived moral culpability of partisan outgroups for the endorsement of oppositional beliefs. In this paper, I employ an online survey experiment on Amazon Mechanical Turk $(\mathrm{N}=487)$ to assess whether exposure to research on the genetic and biological etiology of political attitudes influences warmth toward partisan outgroups and preferences over political compromise. I present evidence that nontrivial numbers of participants in the treatment group reject the underlying science and do not update their genetic trait attributions for political attitudes. However, I also find that when the treatment is successful at increasing biological and genetic trait attributions, exposure to this research depolarizes strong-identifying partisans. Moreover, as partisans increasingly endorse biological and genetic trait attributions for political attitudes, they increasingly hold favorable attitudes toward political outgroups. These patterns suggest a potentially profitable inroad for political polarization interventions going forward.
\end{abstract}

Word Count: 209 words

Keywords: polarization; biopolitics; ideology; trait attributions; survey experiment 
On June 1, 2019, Democratic primary candidate Andrew Yang tweeted, "According to twins $[$ sic] studies between one-third and one-half of political alignment is linked to genetics; that is most of us are born somewhat wired to be liberal or conservative. If this is the case we need to build bridges as much as possible. It's not just info or culture" (Yang 2019). Yang's tweet is notable as it suggests that one potential strategy to reduce growing partisan antipathy (Iyengar et al., 2012; Kalmoe and Mason 2019) is to raise public awareness of recent research in political science which demonstrates that a sizable proportion of individual-level variation in political attitudes can be explained by biological and genetic factors (Dawes and Fowler 2008; Hatemi and McDermott 2012). The unstated assumption of this argument is that it is difficult to hold members of political outgroups responsible for the endorsement of oppositional political beliefs when variation in such beliefs is best predicted by ascriptive factors over which individuals have no control. Thus, in this view, awareness of the biological substrates of political attitudes and of the minimized role of personal choice in generating those attitudes should increase political tolerance toward partisan outgroups as "born that way"-style explanations partially absolve members of partisan outgroups of the perceived evilness of their belief systems (Snead 2011; Schneider, Smith, and Hibbing 2018).

However, it is also imaginable that exposure to information on the biological and genetic sources of political attitudes could further animate partisan tensions. Instead of this information being used to exculpate members of political outgroups of the perceived offense of their beliefs, exposure to this information might cause individuals to view the partisan gulf as elementally unbridgeable. In this perspective, exposure to the degree of determinism implied by biological models of political attitudes could reduce perceptions that members of political outgroups are capable of opinion-change. Thus, if the political attitudes of partisan outgroups are viewed as increasingly resistant to change given the biological forces which underlie them, then it follows that partisans might increasingly disengage from meaningful social interactions with those across the aisle and come to devalue having conversations with their outpartisan counterparts. Moreover, belief in the relative fixity of the political attitudes 
of partisan outgroups could potentially translate into the adoption of more exaggerated and essentialist views of the other (Haslam and Whelan 2008).

Although two studies have investigated the extent to which individuals perceive political attitudes as being genetically-determined (Schneider, Smith, and Hibbing 2018; Willoughby et al. 2019), no studies have yet investigated how exposure to this research might condition attitudes toward political outgroups. It is worth considering the efficacy of this strategy as a potential mechanism to temper partisan animosities, particularly in an era of accented affective polarization and given heightened levels of scholarly and media interest in the subject of biopolitics in recent years.

To test whether exposure to information on the neurobiological and genetic basis of political belief influences tolerance toward political outgroups, I conducted a survey experiment on Amazon Mechanical Turk in August 2019 ( $\mathrm{N}=487)$. In this study, I assessed whether exposure to an article describing the emerging biological science of ideology and partisanship influenced levels of affective partisan polarization and preferences for political compromise. My results suggest that exposure to research on the neurobiological and genetic basis of political belief conditionally decreased affective polarization. While interestingly a nontrivial proportion of participants in the treatment group did not appear to update their attitudes about the biological basis of political attitudes, a series of causal mediation analyses revealed that among those who accepted the underlying science, political tolerance increased: Democrats adopted warmer attitudes toward Republicans, and Republicans adopted warmer attitudes toward Democrats. However, the experimental treatment did not influence more domain-general preferences over political compromise or viewpoint diversity. Finally, it is worth noting that although the experimental treatment was not uniformly effective at increasing belief in the underlying biological underpinnings of political belief, greater endorsement of the biological foundations of political belief significantly predicted increased warmth toward political outgroups across conditions. This result notably contrasts with the findings of Schneider, Smith, and Hibbing (2018) who report that the acceptance of genetic trait attributions predicted 
decreased tolerance of ideological outgroups.

In what follows, I survey extant research in moral psychology and neuroscience on freewill beliefs and their association with moral culpability as well as political science scholarship on trait attributions and affective polarization. I proceed to discuss the design of my survey experiment, methodology, and empirical results. I conclude by considering the implications of my findings for future research.

\section{On The Moral Implications of Free Will}

We often operate under the assumption that we are in control of our choices and that the decisions we arrive at reflect some element of free-will. A recent survey by Scientific American found that approximately $60 \%$ of Americans believe in free-will (Stix 2015). When asked to evaluate our own decision-making and the decision-making of others, we often default to this presumption of agency, and our subjective experiences interfacing with the world often are enough to, at least momentarily, convince us that we are the primary architects of our lived experience (Nahmias et al. 2005; Condit et al., 2006).

In moral philosophy, volitionalists argue that this ability to freely-choose is a necessary precondition of moral responsibility (Levy 2005; Nichols 2006). Similarly, most penal codes and religious institutions presuppose the validity of the volitionalist approach to moral reasoning. In the criminal justice system, choice and intentionality are widely-accepted determinants of punishment severity. For instance, criminal insanity defenses are often mounted to mitigate punishment of individuals of diminished mental capacity, and individuals convicted of involuntary manslaughter receive relaxed sentences relative to those who commit voluntary manslaughter (Pereboom 2019). Similarly, foundational notions of sin and forgiveness in many religious traditions often imply an ability to choose freely.

The ability to choose freely influences how we evaluate the morality of actions and

the moral culpability of actors. We tend to hold individuals less accountable for their misdeeds when their capacity to choose freely is impaired. Studies in social psychology, for 
instance, demonstrate that individuals often make moral evaluations on the basis of intentionality (Cushman et al., 2013; Astuti and Bloch 2015) and that we are more inclined to forgive accidental, as opposed to intentional, violations (Young 2009; Baumeister and Brewer 2012; Shariff et al. 2012). Increasingly, criminologists have called for changing criminal law to reflect the fact that criminals with psychopathy are biologically incapable of understanding the moral weight of their antisocial behaviors (Glenn, Raine, and Laufer 2011; Umbach, Berryessa, and Raine 2015). Thus, belief in free will, or at least the subjective experience of it, seems to weigh heavily in how we morally reason about the world and evaluate the blameworthiness of moral agents.

\section{Political Beliefs and the Question of Free Choice}

We tend to perceive our own ideological beliefs as being the byproduct of a Downsian form of rational and conscious deliberation, reflecting a cooly objective appraisal of the costs and benefits of one policy over another (Downs 1957). In this account, we perceive the menu of political beliefs individuals endorse as being intentionally chosen. This assumption that people choose their political beliefs thus leads us to underemphasize nonvolitional sources in explaining why people hold the political beliefs that they do. To this point, Schneider, Smith, and Hibbing (2018) assessed the types of attributions individuals make for various traits. In their study, they asked participants to assess the extent to which specific traits (e.g., height, weight, criminality, ideology) are attributable to genetic influences, environmental influences, or to personal choice. One of the most interesting conclusions of their study is that individuals tend to believe that ideological beliefs are predominantly a matter of personal choice, with the average participant stating that approximately $54 \%$ of variation in ideology reflects personal choice, $37 \%$ of this variation reflects the influence of environmental factors, and only $9 \%$ of the variation in ideology reflects genetic factors.

However, recent advances in the fields of political psychology and neuroscience suggest that these lay trait attributions regarding political belief are largely inaccurate and that 
nontrivial variation in our political beliefs can be better explained by neurobiological and genetic factors. For instance, Alford, Hibbing, and Funk (2005) present evidence that political ideology is roughly $40 \%$ heritable and that partisan attachment and other forms of social affiliation are approximately 20\% heritable (Settle, Dawes, and Fowler 2009). Dawes and Fowler (2009) present evidence that the presence of the A2 allele of the D2 dopamine receptor gene significantly predicts an individual's partisan attachment and voter turnout propensity. Oxley et al. (2008) demonstrate that physiological reactivity to threat predicts preferences over an array of policies. Nascent evidence from neuroscience suggests brain morphology and activation may also shape ideological leanings. For example, Kanai et al. (2011) present evidence that greater liberalism correlates positively with increased gray matter volume in the anterior cingulate cortex and conservatism with larger right amygdala volume. Tritt et al. (2016) present evidence that conservatives exhibit heightened levels of neural reactivity and arousal in response to exposure to positive and negative stimuli. And more recently, Nam et al. (2018) present evidence that larger bilateral amygdala volume correlates positively with system justification beliefs.

Taken together, the conclusions of these studies increasingly challenge our default assumption that political beliefs and affinities are largely the byproduct of unencumbered personal choice. This inaccuracy in perception matters and has important social and political consequences. The perception that political beliefs are chosen freely versus being, in some sense, hard-wired and that individuals are morally responsible for the policy positions which they adopt seems to be one of the most elemental presuppositions underlying the recent uptick in affective partisan polarization. To this point, Kalmoe and Mason (2019) present evidence that over $40 \%$ of Democrats and Republicans agree that partisans on the other side of the aisle "are not just worse for politics - they are downright evil." As with sin, the notion of evilness implies the capacity to make a choice. However, if individuals do not freely choose their beliefs and are instead operating under the constraints of their own biological and genetic programming, then arguably a nontrivial proportion of the widening partisan divide could be 
rooted in an ostensibly fixable misconception.

However, it is worth noting that exposure to research on the underlying neurobiology and genetics of political belief may not be sufficient to exculpate members of partisan outgroups of the perceived sin of their belief systems. For instance, a series of studies in moral psychology demonstrate that exposure to deterministic arguments which undermine the basis for a belief in free-will reduces prosocial behavior and decreases feelings of gratitude (Vohs and Schooler 2008; Baumeister, Masicampo, and DeWall 2009; MacKenzie, Vohs, and Baumeister 2014). Thus, it is conceivable that exposure to research on the underlying neurobiology and genetics of political belief could cause partisans to perceive outpartisans less charitably as they come to perceive members of the partisan outgroup as increasingly resistant to persuasion attempts and more entrenched in their beliefs overall. Given the rise in affective partisan polarization in recent years as well as the increased scholarly interest in genopolitics over the past decade, it is worth exploring whether the optimism of the Yang-ian premise holds to assess how, if at all, exposure to underlying science of political attitudes influences political tolerance and preferences over compromise.

\section{Methods}

To assess whether exposure to research on the neurobiology and genetics of political belief conditions attitudes toward political outgroups and willingness to compromise, I conducted an online survey experiment in August 2019 on Amazon Mechanical Turk $(N=487)^{1}$. In order to participate in the study, I only included participants who were U.S. citizens and who were 18 years of age or older.

In the survey experiment, I randomly assigned participants to either a treatment condi-

\footnotetext{
${ }^{1}$ It is worth briefly commenting on the use of Amazon Mechanical Turk convenience samples given the familiar objection to the use of these samples on generalizability grounds. While it is worth noting that Amazon Mechanical Turk workers tend to, on average, be more highly-educated, white, and ideologically liberal than the U.S. population at large and while it is worth being mindful of these imbalances, recent research suggests that potential concerns over self-selection effects have been overstated and that the use of such samples does not appreciably bias estimates of treatment effects relative to survey experiments which employ more representative samples. See, for instance, recent work by Mullinix et al. (2015) and Coppock (2019).
} 
tion where they read a short article summarizing recent research on the neurobiological and genetic basis of political attitudes or to a control condition where they read a short neutral article (see Appendix A for text of these two frames). Condition randomization worked as intended $^{2}$. Following the experimental manipulation and attention check, I then assessed a series of trait attributions by asking participants to identify on a 100 point scale the degree to which they thought various traits, including ideology and party identification, were attributable to personal choice, socialization, and biological and genetic factors. Following this, I assessed levels of affective partisan polarization with a 100-point feeling thermometer scale and preferences for political compromise (see Appendix D for more details on question wording and coding). I then collected demographic information, including information about participants' partisan and ideological identifications. Finally, I debriefed participants and thanked them for their participation in the study. Following successful verification of survey completion, I paid participants $\$ 0.50$ for their participation.

\section{Results}

First, it is worth assessing whether reading about the neurobiological and genetic etiology of political attitudes increased participants' perceptions that political ideology is a byproduct of biological influences. To that end, I first assessed differences in biological and genetic trait attributions between participants in the treatment and control condition. As described earlier, the trait attribution measure asks participants to identify the extent to which they perceive a given trait as being determined by genetic and biological factors, environmental factors, and personal choice. As a reference point, Schneider, Smith, and Hibbing (2018) reported that individuals largely discount the explanatory role of genetic influences in predicting ideology, finding that on average participants attributed $8.2 \%$ of variation in political beliefs to genetic factors. Willoughby et al. (2019) report similar results suggesting that individuals, in general,

\footnotetext{
${ }^{2}$ I assessed covariate balance by regressing a treatment indicator on a set of covariates in a logistic regression model. No covariates achieved statistical significance at conventional levels $(\alpha=0.05)$. Sample summary statistics are available in Appendix B, and the results of the covariate balance check are available in Appendix C.
} 
downplay or may simply be unaware of the biological and heritable components of political beliefs. My results are consistent with the conclusions of these two studies. In the control condition, participants attributed $10.36 \%$ of variation in political ideology to genetic and biological influences. In the treatment condition, participants attributed $23.35 \%$ of variation in ideology to genetic and biological influences. As Figure 1 indicates below, this difference was statistically-significant and in the predicted direction, suggesting that the treatment worked as intended $(F=59.12, p<0.01)$. A similar effect emerged for party affiliation such that participants made significantly greater biological trait attributions in the treatment condition as observed in Figure $2(F=50.76, p<0.01)^{3}$.

It is worth noting that although the treatment significantly increased participants' beliefs in the predictive power of biological and genetic influences over political belief, the treatment was not universally effective. For instance, approximately $57.8 \%$ of participants $(138 / 239)$ in the control condition stated that biological and genetic influences played no role whatsoever in predicting ideology. In the treatment group, however, $18.21 \%$ of participants $(45 / 247)$ stated that biological and genetic influences played no role in predicting ideology. This result held even after excluding participants who failed to pass an attention check. Thus, there appears to be some resistance to the endorsement of the science described in the treatment condition which cannot simply be explained away by participant inattention. I initially suspected that this resistance could be explained by either low levels of trust in scientific expertise or by the general primacy of personal-growth mindsets as a proxy for free-will beliefs. First, it might be that individuals who distrust science in general simply reject the manipulation's scientific frame outright. Alternatively, it might be that individuals who score higher in personal growth-mindset beliefs would be psychologically motivated to reject the conclusions of this research which, given the determinism implied therein, could be perceived as antagonistic to their more centralized and stable beliefs about the human capacity to change (Dweck 2008).

\footnotetext{
${ }^{3}$ It is worth noting that genetic trait attributions for ideology and partisanship are similar in size and statistical significance and predictably correlate positively $(\mathrm{r}=0.68, \mathrm{~N}=483$, p-value $<0.01)$. Thus, in the analysis presented in this paper and for the sake of parsimony, I utilize ideological genetic trait attributions as a key predictor. The results for genetic trait attributions of partisanship are nearly identical.
} 


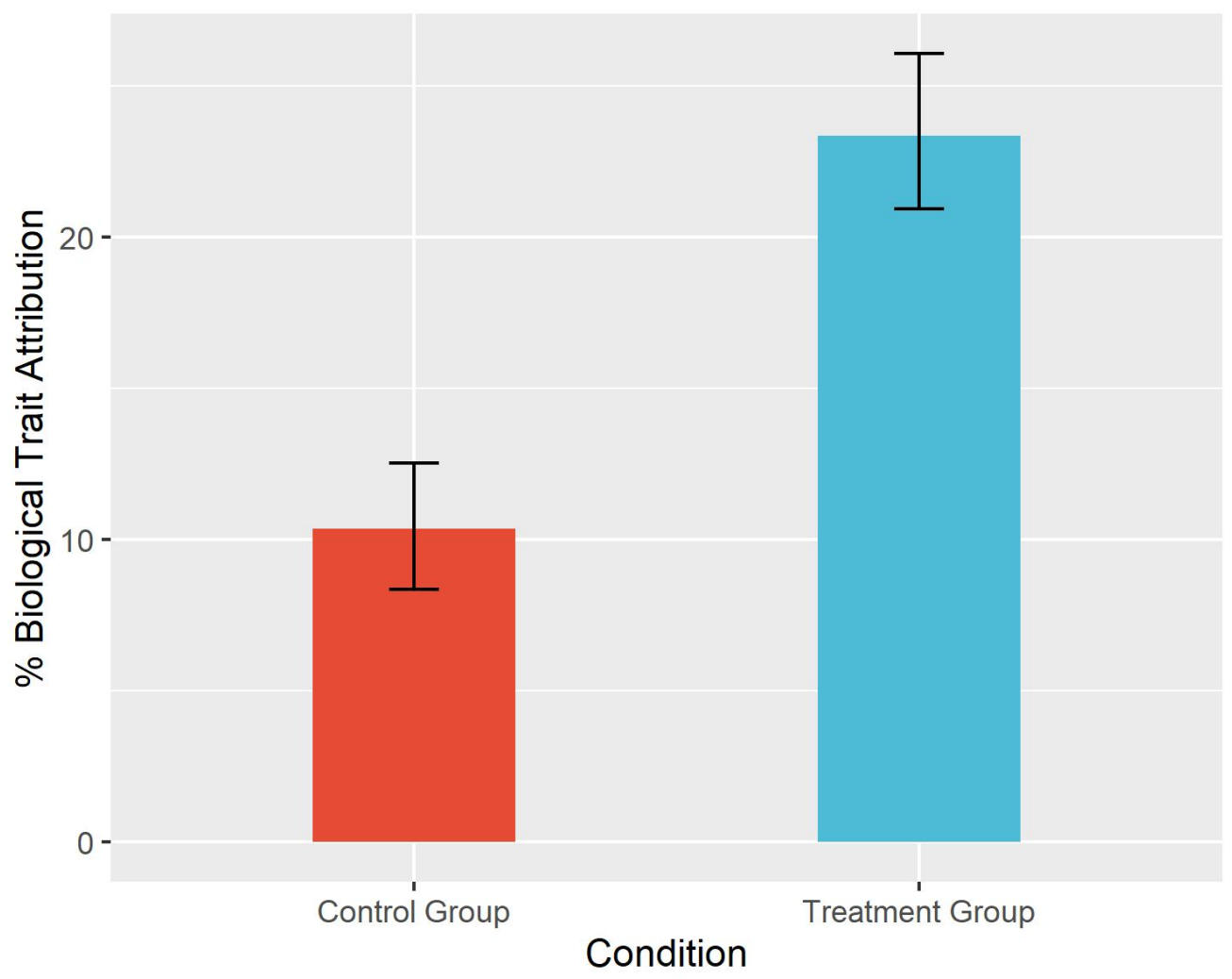

Note: Average of biological and genetic trait attribution for ideology between control group and treatment group with $95 \%$ confidence intervals. $\mathrm{N}=487$.

Thus, to assess which factors predicted endorsement of genetic trait attributions for ideology, I regressed genetic trait attributions on demographic covariates, a measure of trust in science, and a three-item additive scale of fixed-mindset beliefs ${ }^{4}$. I present the results of Model 1 below in Table 1.

The results from Table 1 suggest that participants who endorsed a fixed-growth mindset (e.g., those who view people as less capable of change) were more likely to endorse genetic trait attributions for ideology ${ }^{5}$. Of note, more religious participants and those from higher

\footnotetext{
${ }^{4}$ I also ran a series of models where I included treatment assignment as a covariate in the model as well as two split-sample regressions by condition. The statistical significance of the results is substantively unchanged, though the effect size for the treatment variable predictably dwarfs the magnitude of coefficient estimates for other relevant covariates. Further, when treatment is included as a covariate, the coefficient for Male becomes statistically significant.

${ }^{5}$ Importantly, additional unreported regressions suggest that treatment assignment did not predict scores on the fixed-growth mindset scale.
} 


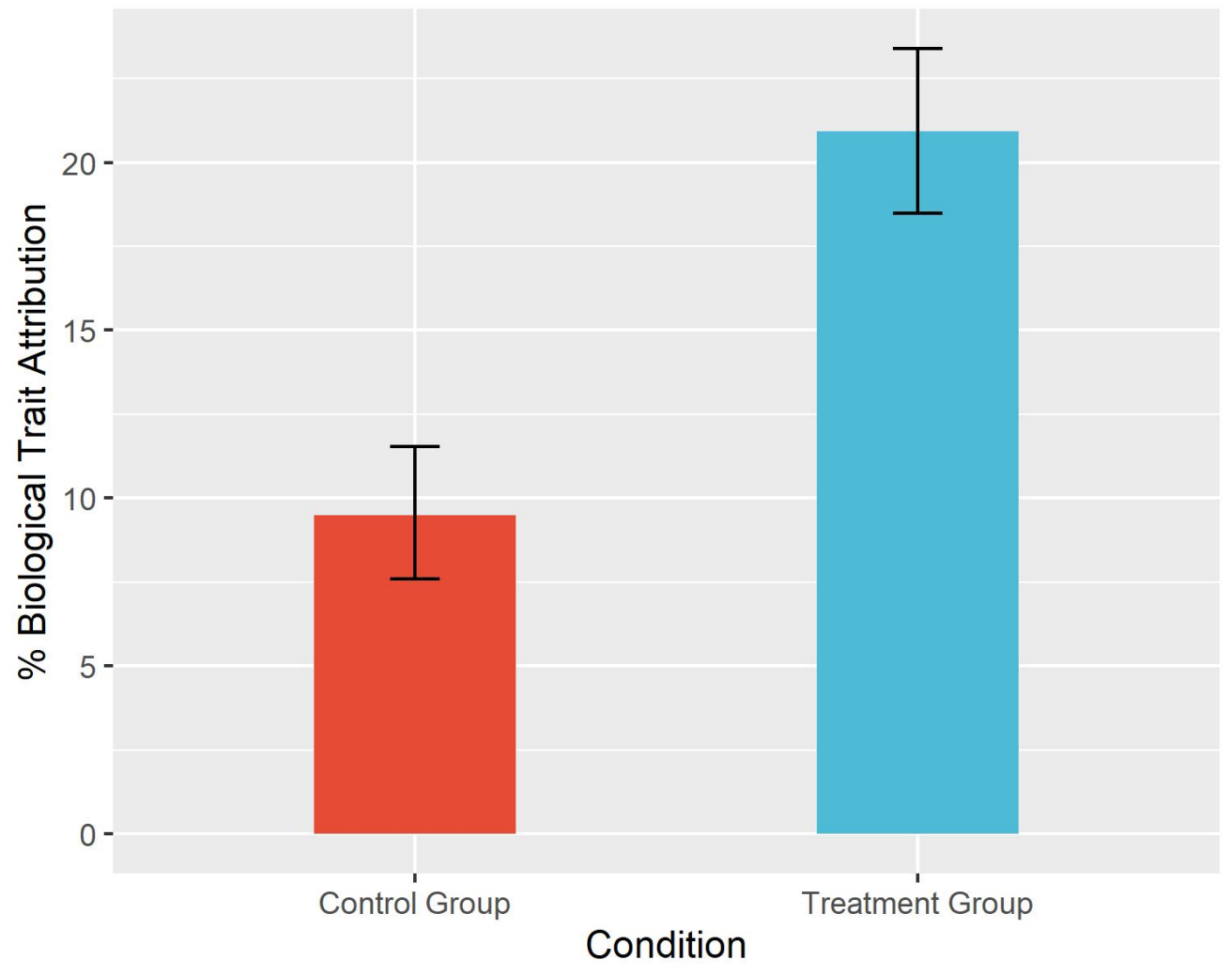

Note: Average of biological and genetic trait attribution for party identification between control group and treatment group with $95 \%$ confidence intervals. $\mathrm{N}=487$.

social classes were more likely to accept biological trait attributions whereas participants who scored higher on the political knowledge index were significantly less likely to accept biological trait attributions. Notably, trust in science did not significantly predict the endorsement of genetic trait attributions.

Next, I conducted a multivariate ordinary least squares regression to assess whether the endorsement of genetic trait attributions predicted greater warmth toward members of political outgroups. To this end, I regressed feeling thermometer scores on genetic trait attributions for Republicans and Democrats and the same set of covariates used in Model 1. To ease aid of interpretation, I rescaled the genetic trait attribution variable, dividing it by one-hundred, such that a one unit increase in the genetic trait attribution variable can be interpreted substantively as a 100 percentage point increase in the endorsement of the genetic 
Table 1: What Predicts Greater Endorsement of Genetic Trait Attributions?

\begin{tabular}{lc}
\hline & Model 1 \\
\hline Trust in Science & $-1.07(1.10)$ \\
Dweck Scale & $0.75^{* * *}(0.24)$ \\
Age & $-0.01(0.08)$ \\
Sex: Male & $2.62(1.85)$ \\
Race: White & $-1.91(2.02)$ \\
Education & $0.73(0.69)$ \\
Religiosity & $1.51^{* *}(0.73)$ \\
Party Identification & $0.07(0.62)$ \\
Ideology & $-0.89(0.80)$ \\
Subjective Class & $3.40^{* *}(1.41)$ \\
Income & $-0.87(0.71)$ \\
Employment & $-0.77(0.91)$ \\
Political Knowledge & $-3.58^{* * *}(1.27)$ \\
Political Interest & $0.50(0.84)$ \\
Constant & $10.77(7.85)$ \\
\hline Observations & 474 \\
$\mathrm{R}^{2}$ & 0.094 \\
Adjusted R $\mathrm{R}^{2}$ & 0.066 \\
Residual Std. Error & $19.15(\mathrm{df}=459)$ \\
F Statistic & $3.39^{* * *}(\mathrm{df}=14 ; 459)$ \\
\hline Note: & ${ }^{*} \mathrm{p}<0.1 ;{ }^{* *} \mathrm{p}<0.05 ;{ }^{* * *} \mathrm{p}<0.01$
\end{tabular}

Note: Ordinary least squares specification with the biological genetic trait attribution variable specified as the dependent variable.

trait attribution. I reproduce the results of these models graphically in Figure 3 and Figure 4 below.

My results suggest that as participants increasingly perceived genetic and biological factors as predictive of ideological belief, affective partisan polarization toward political outgroups decreased. To provide a substantively meaningful interpretation of the magnitude of this effect, we can contrast the extreme cases of partisans who believe that genetic and biological factors play no role in predicting ideological belief to partisans who believe that genetic and biological factors are completely determinative of political belief. Thus, if we contrast a hypothetical Democrat who believed that biological and genetic factors had no influence on 
Figure 3: Effect of Biological Ideological Trait Attribution (\%) on Warmth Toward Republicans

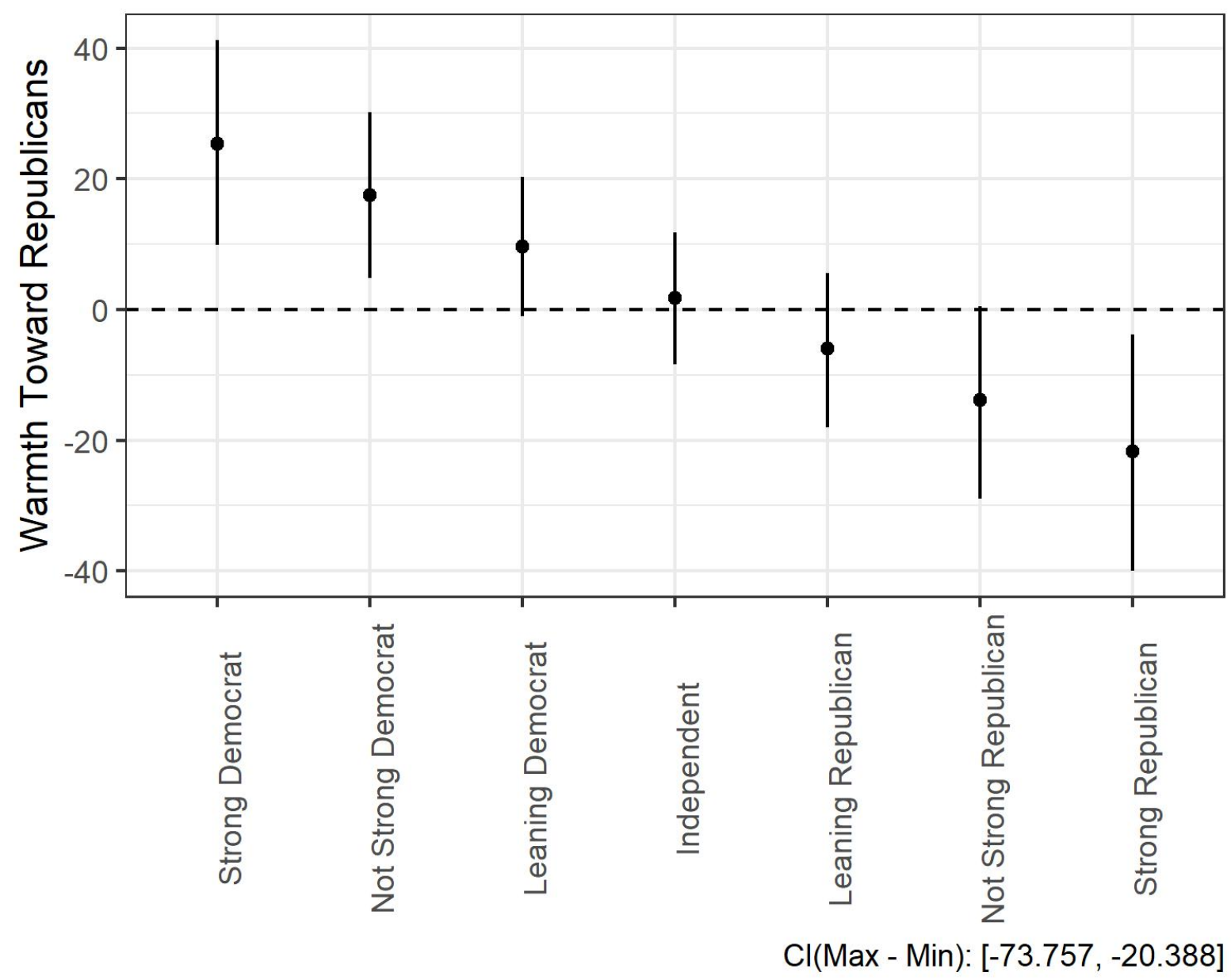

Note: This plot displays the predicted effect of the endorsement of genetic trait attributions for ideology on warmth toward Republicans as measured on the 100 point feeling thermometer scale with $95 \%$ confidence intervals. As the genetic trait attribution variable has been rescaled between 0 and 1 where a value of 0 indicates that the participant does not believe genetics plays any role in explaining ideological variance and a score of 1 indicates that the participant believes that genetics accounts for the entirety of ideological variance, the plot shows, across varying levels of partisanship, how much warmth toward Republicans increases as belief in the percentage variance in ideology explained shifts from $0 \%$ to $100 \%$.

ideological beliefs against a hypothetical Democrat who believed that biological and genetic factors completely determined ideology, warmth toward Republicans would be expected to increase by a significant 26 points on the 100 point feeling thermometer scale as demonstrated in Figure 3 (p-value $<0.01$ ). Similarly, if we contrast a hypothetical Republican who believed that biological and genetic factors had no influence on ideological beliefs against a hypothetical Republican who believed that biological and genetic factors completely determined ideological 
Figure 4: Effect of Biological Ideological Trait Attribution (\%) on Warmth Toward Democrats

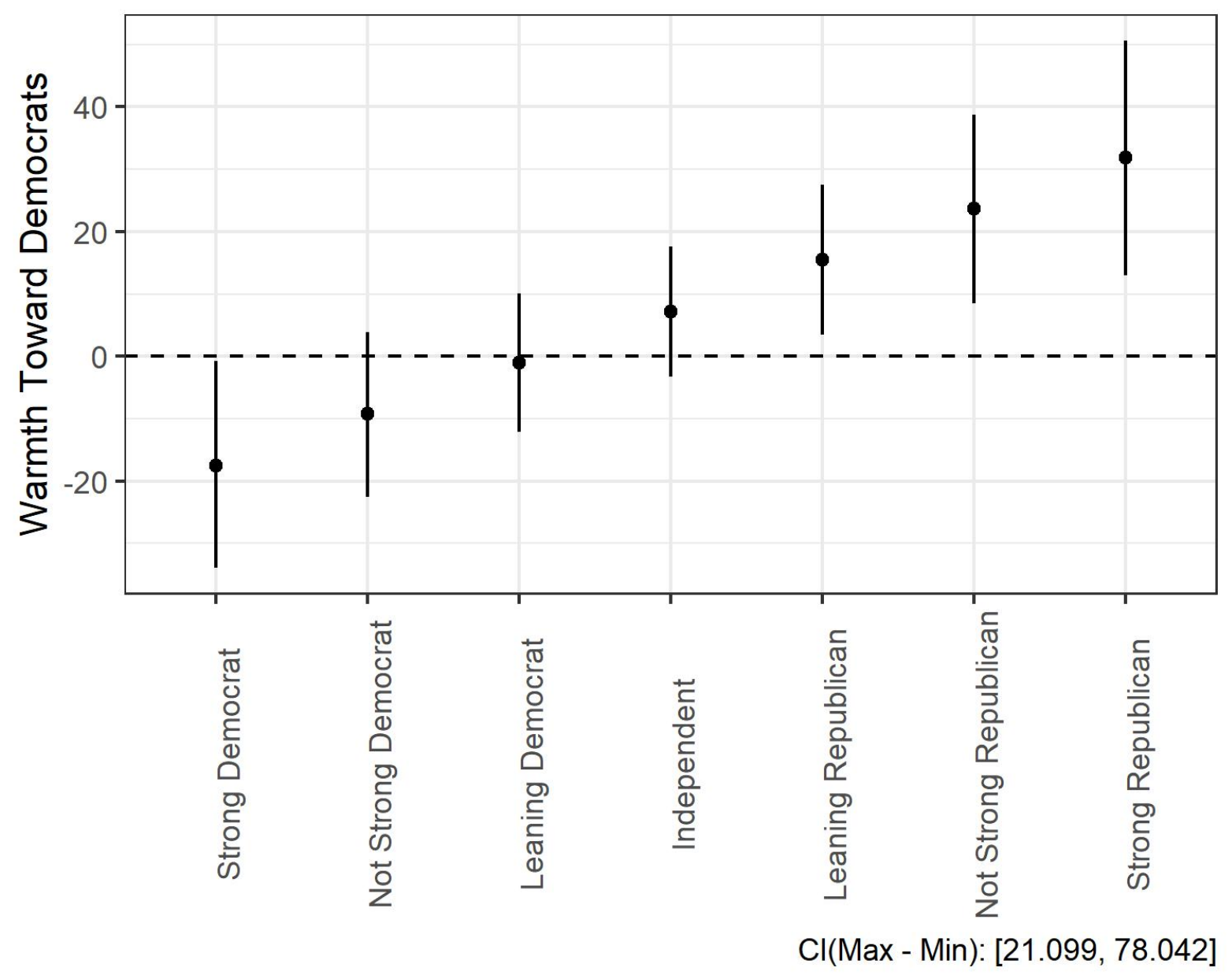

Note: This plot displays the predicted effect of the endorsement of genetic trait attributions for ideology on warmth toward Democrats as measured on the 100 point feeling thermometer scale with $95 \%$ confidence intervals. As the genetic trait attribution variable has been rescaled between 0 and 1 where a value of 0 indicates that the participant does not believe genetics plays any role in explaining ideological variance and a score of 1 indicates that the participant believes that genetics accounts for the entirety of ideological variance, the plot shows, across varying levels of partisanship, how much warmth toward Democrats increases as belief in the percentage variance in ideology explained shifts from $0 \%$ to $100 \%$.

beliefs, all else equal, warmth toward Democrats would be expected to increase by a significant 32 points as demonstrated in Figure 4 (p-value $<0.01$ ).

Given that endorsement of genetic trait attributions in turn predicted greater warmth toward political outgroups, it is worth assessing whether the treatment, in turn, influenced this relationship. To this end, I used ordinary least squares regression to regress feeling thermometer scores towards Republicans and Democrats on the interaction of treatment assignment with 
the seven-point party identification scale. I first assessed the effect of treatment assignment on affect toward Republicans by party affiliation (Model 2). I proceeded to assess the effect of treatment assignment on affect toward Democrats (Model 3), and then I assessed the effect of treatment assignment on the difference in feeling thermometer scores, the common measure of affective partisan polarization employed in the literature (Model 4). I present the results of these models in Table 2 below.

Table 2: Average Treatment Effect on Measures of Polarization

\begin{tabular}{|c|c|c|c|}
\hline & Model 2 & Model 3 & Model 4 \\
\hline Condition & $\begin{array}{r}8.23^{*} \\
(4.74)\end{array}$ & $\begin{array}{r}-0.28 \\
(5.23)\end{array}$ & $\begin{array}{c}8.51 \\
(6.47)\end{array}$ \\
\hline Party ID & $\begin{array}{l}11.60^{* * *} \\
(0.68)\end{array}$ & $\begin{array}{c}-8.90^{* * *} \\
(0.75)\end{array}$ & $\begin{array}{c}20.50^{* * *} \\
(0.92)\end{array}$ \\
\hline Condition:Party ID & $\begin{array}{c}-1.89^{* *} \\
(0.94)\end{array}$ & $\begin{array}{c}0.07 \\
(1.04)\end{array}$ & $\begin{array}{r}-1.96 \\
(1.28)\end{array}$ \\
\hline Constant & $\begin{array}{c}-9.34^{* * *} \\
(3.46)\end{array}$ & $\begin{array}{l}96.83^{* * *} \\
(3.81)\end{array}$ & $\begin{array}{c}-106.17^{* * *} \\
(4.72)\end{array}$ \\
\hline Observations & 485 & 485 & 485 \\
\hline $\mathrm{R}^{2}$ & 0.52 & 0.38 & 0.66 \\
\hline Adjusted $\mathrm{R}^{2}$ & 0.51 & 0.37 & 0.66 \\
\hline Residual Std. Error $(\mathrm{df}=481)$ & 22.29 & 24.60 & 30.43 \\
\hline F Statistic $(\mathrm{df}=3 ; 481)$ & $171.91^{* * *}$ & $97.47^{* * *}$ & $308.67^{* * *}$ \\
\hline
\end{tabular}

Note: Ordinary least squares specification with affect toward Republicans (Model 2), affect toward Democrats (Model 3), and the difference between inparty and outparty evaluations (Model 4) specified as the dependent variables and treatment assignment, the seven-point measure of party identification, and their interaction specified as the independent variables.

The results from Table 2 demonstrate that the interaction of treatment assignment and party affiliation was significant for the Republican feeling thermometer only ( $\mathrm{p}$-value $=0.05$ ). However, as noted previously, there appears to be a considerable number of participants in the treatment condition who did not update their beliefs about the underlying science in response to the experimental manipulation. Thus, it is important to assess whether heterogeneity in the treatment effect exists and whether this heterogeneity is conditioned by acceptance of 
the underlying science of the experimental manipulation (Gaines and Kuklinski 2011). As the treatment does not uniformly increase belief in the genetics of political attitudes among approximately $37.7 \%$ of those in the treatment group (93/247) who report that neurobiological and genetic factors play less than a $10 \%$ role in predicting ideology ${ }^{6}$, attempts at estimating average treatment effects without accounting for the treatment's seeming failure among this subgroup of non-updaters may obscure the effect of the treatment among those participants for whom the treatment effectively increased biological and genetic trait attributions.

Because treatment exposure predicted increased endorsement of biological and genetic trait attributions and because these trait attributions, in turn, predicted partisans' warmth toward political outgroups, I conducted a series of causal mediation analyses to assess whether acceptance of the genetic framing, as proxied by the endorsement of genetic trait attributions, mediated the nonsignificant effect of the treatment on the relevant outcome measures. Although it is commonly assumed that the average treatment effect must achieve statistical significance in order to conduct mediation analysis, recently psychometricians have argued that mediation analysis is still an appropriate technique to deploy if there are theoretical reasons for anticipating indirect effects. Accordingly, as I argue that the acceptance of the underlying science is a necessary precondition for the treatment to influence levels of affective polarization, I follow Rucker et al.'s (2011) recommendation to conduct causal mediation analysis.

To this end, I employ the use of counterfactual causal mediation analysis as formulated by Imai, Keele, and Yamamoto (2010). To recapitulate the logic of this methodological choice, the experimental treatment should presumably influence political tolerance but only to the extent that the treatment increased participants' endorsement of biological and genetic trait attributions. In other words, a necessary precondition for the treatment to theoretically influence affective polarization and preferences over political compromise would be through the increased endorsement of genetic trait attributions that the treatment engenders.

\footnotetext{
${ }^{6}$ I used the $10 \%$ threshold as this was the average biological trait attribution of participants in the control group.
} 
Of primary interest for the purposes of this analysis is the Average Causal Mediation Effect (ACME). The ACME should be interpreted as the overall treatment effect on the outcome variable which is explained through varying levels of the proposed mediator: biological and genetic trait attributions. Thus, analyzing the ACME has the benefit of explicitly modeling the treatment and mediator interaction without the potential statistical power losses and bias-introduction associated with dropping participants who failed to update trait attributions in response to the treatment (Aronow, Baron, and Pinson 2018).

For the purposes of this analysis, I first divided the sample into subsamples of Democratic and Republican participants. Thus, I combined Strong Democrats, Not Strong Democrats, and Leaning Democrats into a subgroup and Strong Republicans, Not Strong Republicans, and Leaning Republicans into a separate subgroup. I then conducted causal mediation analysis within each subgroup using the mediation package in $\mathrm{R}$, specifying treatment as the primary explanator, the ideological gene trait attribution as the mediator, and feeling thermometer scores for the outgroup as the dependent variable (Tingley et al., 2014). I graphically present the results of this analysis below based off of 1000 bootstrapped samples with $90 \%$ confidence intervals and robust standard errors. Figure 5 displays the results for all Democrats and Strong Democrats and Figure 6 for all Republicans and Strong Republicans.

Biological and genetic trait attributions mediated the nonsignificant effect of experimental condition on participants' attitudes toward political outgroups. Figure 5 demonstrates that when Democrat participants endorsed biological trait attributions in response to the treatment, on average, they felt 3.92 points warmer toward Republicans (p-value $<0.03$ ). This effect is statistically significant, albeit admittedly small substantively. However, this depolarization effect is considerably stronger among Strong Democrats. As Strong Democrats increasingly attributed a greater role to biological and genetic factors in response to treatment exposure, they, on average, felt 8.67 points warmer toward Republicans, a substantively larger and statistically significant effect (p-value $<0.01)$.

Figure 6 displays similar results for Republicans. As Republicans increasingly endorsed 
Figure 5: Average Causal Mediation Effects of Biological Trait Attribution (\%) on Warmth Toward Republicans Among Democrats

\section{Republican Affect (All Dems)}

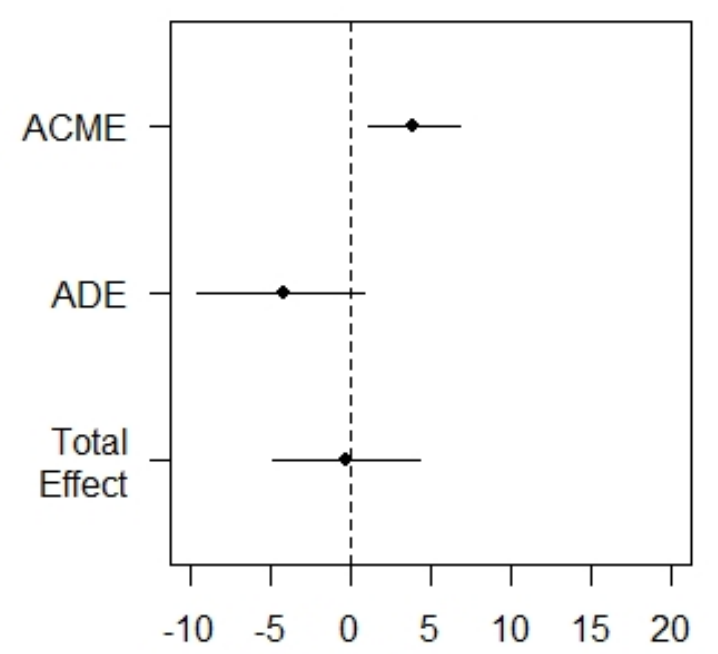

Republican Affect (Strong Dems)

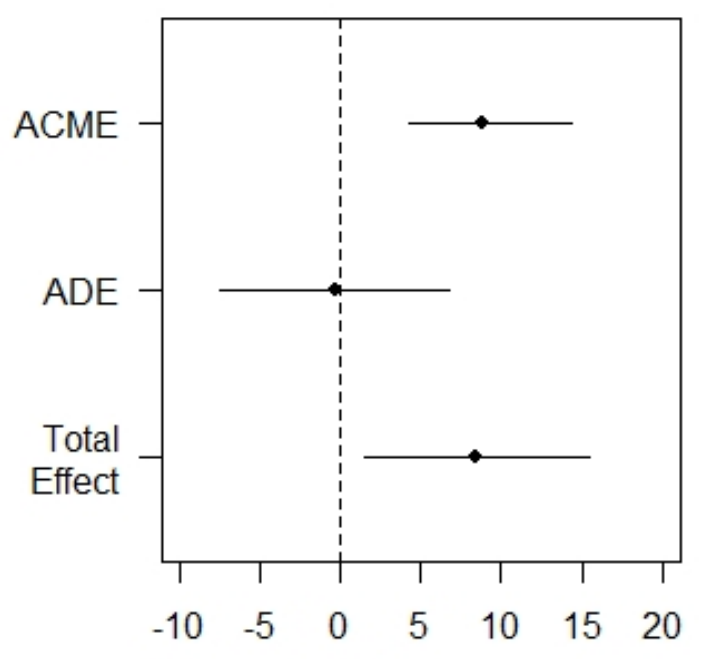

Note: The ACME represents the indirect effect of the treatment transmitted through the mediator, ideological trait attributions. The ADE represents the extent to which affect toward Republicans changes between the control group and treatment group while holding the mediator, ideological trait attribution, constant. The Total Effect represents the overall treatment effect estimate. The estimates are generated from 1000 bootstrapped samples with $90 \%$ confidence intervals.

biological trait attributions in the treatment condition, they on average felt approximately 4.42 points warmer toward Democrats (p-value $<0.00$ ). As Strong Republicans increasingly ascribed a greater role to biological and genetic factors, they, on average, felt 7.38 points warmer toward Democrats ( $\mathrm{p}$-value $<0.03$ ). When I consider overall differences between in-party and out-party evaluations, similar effects obtain as reproduced in Figure 7 below.

Taken together, these results indicate that (a) increased endorsement of biological and genetic trait attributions is positively correlated with warmer attitudes toward political outgroups, (b) although the treatment does increase aggregate endorsement of ideological trait attributions, the extent to which the treatment does so is limited presumably because the manipulation is not strong enough to override more deeply entrenched beliefs about the human 
Figure 6: Average Causal Mediation Effects of Biological Trait Attribution (\%) on Warmth Toward Democrats Among Republicans

Democrat Affect (All Reps)

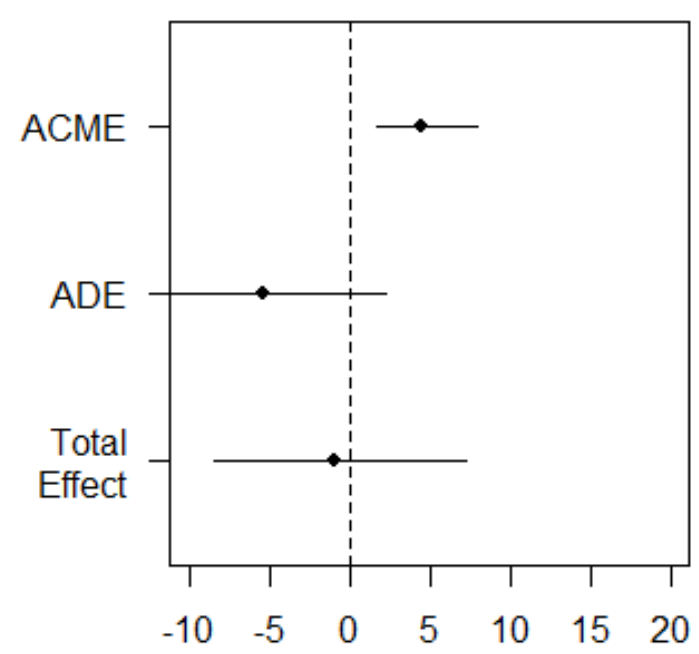

Democrat Affect (Strong Reps)

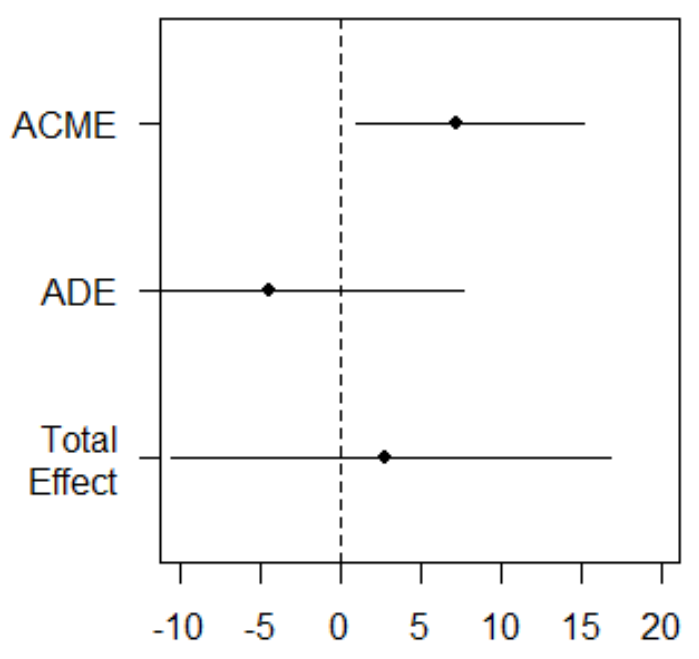

Note: The ACME represents the indirect effect of the treatment transmitted through the mediator, ideological trait attributions. The ADE represents the extent to which affect toward Democrats changes between the control group and treatment group while holding the mediator, ideological trait attribution, constant. The Total Effect represents the overall treatment effect estimate. The estimates are generated from 1000 bootstrapped samples with $90 \%$ confidence intervals.

capacity to change, and (c) that when the treatment does cause participants to increasingly accept genetic trait attributions, exposure to the treatment modestly increases warmth toward political outgroups among Democrats and Republicans and most pronouncedly among strongly-identifying Democrats and Republicans. These results are consistent with theoretical predictions that exposure to information on the genetics of political belief should decrease the likelihood that partisans hold members of political outgroups morally responsible for the endorsement of oppositional belief. Moreover, my findings suggest a potentially effective strategy for bridging the affective partisan divide, particularly among those most likely to be polarized, lending reason for optimism.

Finally, I was also interested in whether exposure to information on the biological and 
Figure 7: Causal Mediation Effects of Biological Trait Attribution (\%) on Overall Affective Polarization

Affective Polarization (Republicans)

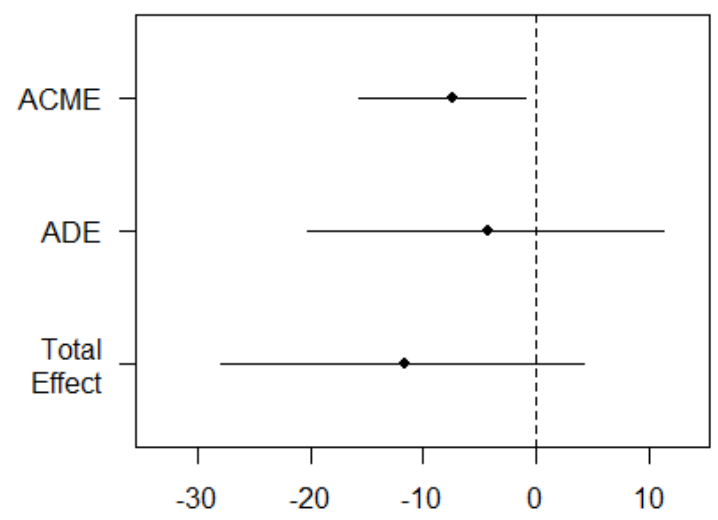

Affective Polarization (Democrats)

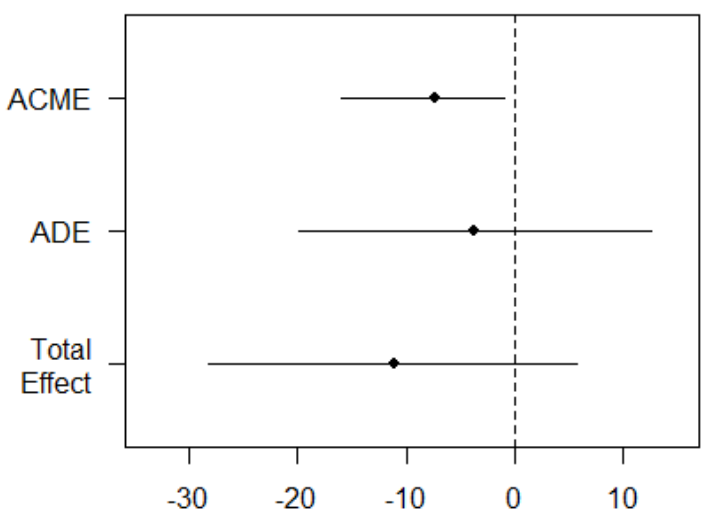

Note: The ACME represents the indirect effect of the treatment transmitted through the mediator, ideological trait attributions. The ADE represents the extent to which differences in ingroup and outgroup feeling thermometer ratings change between the control group and treatment group while holding the mediator, ideological trait attribution, constant. The Total Effect represents the overall treatment effect estimate. The estimates are generated from 1000 bootstrapped samples with $90 \%$ confidence intervals.

genetic roots of political attitudes influenced preferences for political compromise and the perceived value of having politically-diverse discussant partners. Theoretically, we might imagine that exposure to information which emphasizes the biological stickiness of political belief may cause individuals to perceive attempts at persuasion and negotiation as increasingly fruitless. In a similar fashion, if it is the case that individuals perceive ideology as less movable, then it is worth considering whether this, in turn, decreases motivation to engage in dialogue with outpartisans. Thus, to assess whether the treatment influenced preferences over political compromise and viewpoint diversity, I ran three sets of models. In Model 5, I used a logit regression and regressed preferences for general political compromise ${ }^{7}$ on treatment assignment. In Model 6, I used ordinary least squares regression to regress attitudes toward specific compromise between Republicans and Democrats in Congress on the interaction of

\footnotetext{
${ }^{7}$ This preference was assessed by asking participants whether they preferred elected officials who "make compromises with people they disagree with" or prefer elected officials who "stick to their positions."
} 
party identification and treatment assignment. In Model 7, I used ordinary least squares regression and regressed agreement with the statement, "How important is it to you to seek out ideologically-diverse discussion partners?" on treatment assignment. I present the results of these models in Table 3 below.

Table 3: Effect of Treatment on Preferences Over Compromise and Ideological Diversity

\begin{tabular}{|c|c|c|c|}
\hline & Model 5 & Model 6 & Model 7 \\
\hline Treatment & $\begin{array}{c}0.13 \\
(0.19)\end{array}$ & $\begin{array}{c}0.84 \\
(6.70)\end{array}$ & $\begin{array}{c}-0.04 \\
(0.09)\end{array}$ \\
\hline Party Identification & $\begin{array}{l}-- \\
--\end{array}$ & $\begin{array}{l}11.00^{* * *} \\
(1.16)\end{array}$ & $\begin{array}{l}-- \\
--\end{array}$ \\
\hline Treatment: Party Identification & $\begin{array}{l}-- \\
--\end{array}$ & $\begin{array}{c}1.21 \\
(1.61)\end{array}$ & $\begin{array}{l}-- \\
--\end{array}$ \\
\hline Constant & $\begin{array}{l}0.48^{* * *} \\
(0.13) \\
\end{array}$ & $\begin{array}{c}-51.70^{* * *} \\
(4.90) \\
\end{array}$ & $\begin{array}{l}2.92^{* * *} \\
(0.07) \\
\end{array}$ \\
\hline Observations & 485 & 485 & 484 \\
\hline $\mathrm{R}^{2}$ & -- & 0.30 & 0.00 \\
\hline Adjusted $\mathrm{R}^{2}$ & -- & 0.30 & 0.00 \\
\hline Log Likelihood & -318.58 & -- & -- \\
\hline Akaike Inf. Crit. & 641.15 & -- & -- \\
\hline Residual Std. Error & -- & $38.23(\mathrm{df}=481)$ & $0.99(\mathrm{df}=482)$ \\
\hline F Statistic & -- & $69.78^{* * *}(\mathrm{df}=3 ; 481)$ & $0.21(\mathrm{df}=1 ; 482)$ \\
\hline $\begin{array}{l}\text { Note: } \\
\text { Note: Model } 5 \text { displays the results of } \\
\text { specified as the dependent variable. } \\
\text { specific Congressional compromise spe } \\
\text { OLS model with preferences for ideolo }\end{array}$ & $\begin{array}{l}\text { t model w } \\
6 \text { displays } \\
\text { as the de }\end{array}$ & $\begin{array}{l}\qquad{ }^{*} \mathrm{p}<0.1 ; \\
\text { references for general poli } \\
\text { results of an OLS model } \\
\text { lent variable. Model } 7 \text { dis } \\
\text { issant partners specified a }\end{array}$ & $\begin{array}{l}\mathrm{p}<0.05 ;{ }^{* * *} \mathrm{p}<0.01 \\
\text { al compromise } \\
\mathrm{h} \text { preferences for } \\
\text { ys the results of an }\end{array}$ \\
\hline
\end{tabular}

My results indicate that the treatment does not influence generalized preferences for political compromise, specific preferences for political compromise in congressional negotiations, or the extent to which individuals value ideological-diversity in political discussant partners. Further, these results are robust to unreported mediation specifications described earlier using biological trait attributions for ideology as the mediator. Taken together, this set of results suggest that while depolarization interventions which emphasize the science of ideology may generally help reduce affective partisan polarization, they neither deter nor en- 
hance prospects for political compromise or participants' desires to seek out political diversity in their discussion networks.

\section{Conclusion}

To summarize, in this paper, I used an online survey experiment to assess whether exposure to recent scientific findings on the neurobiology and heritability of political belief influenced affective polarization and preferences over compromise. Theoretically, a priori, it was unclear whether such a strategy would increase or decrease levels of affective partisan polarization. On the one hand, a subset of researchers in philosophy and moral psychology have found that individuals tend to be more forgiving when they perceive that individuals have less control over their decisions (Young 2009; Baumeister and Brewer 2012; Shariff et al. 2012). Conversely, other researchers in social psychology have found that individuals become more antisocial when their belief in free-will and choice is undermined (Vohs and Schooler 2008; Baumeister, Masicampo, and DeWall 2009; MacKenzie, Vohs, and Baumeister 2014). Thus, one of the goals of the present research was to provide a preliminary test of these two divergent theoretical predictions to assess which, if either, held in the context of the debate about the degree of determinism of political belief.

In this paper, I present evidence, consistent with recent work by Schneider, Smith, and Hibbing (2018) and Willoughby et al. (2019), that most people view ideological beliefs and partisanship as being largely determined by personal choice and to a lesser degree by socialization. Individuals are either unaware of or are psychologically-resistant to the idea that political beliefs are even partially the byproduct of biological and genetic processes. Further, although the experimental manipulation increased beliefs that ideology is biologically-determined, the manipulation was not uniformly effective. However, among those who responded to the manipulation, affective polarization decreased in a rather pronounced fashion, particularly among strongly-identifying partisans. Moreover, across both conditions, increased endorsement of biological and trait attributions correlated positively with the endorsement of warmer attitudes 
toward political outgroups. Finally, my study demonstrated that exposure to such a frame does not appreciably shift attitudes toward political compromise or whether participants felt it was important to have ideologically-diverse discussant partners.

However, it is worth noting a few limitations to the present paper which suggest promising avenues for future research. First, the current design cannot rule out the possibility that any narrative which outsources responsibility for political beliefs to an external locus may promote depolarization. To this end, future studies should contrast the strength of depolarization effects between frames which emphasize the underlying biological science of ideology against frames which emphasize the role of socialization factors, frames which would similarly imply that individuals are not fully-responsible for their own political beliefs. Secondly, in the present study, I did not directly measure perceptions of the moral culpability or blameworthiness of political outgroups. Future work should investigate whether exposure to frames which minimize the role of personal choice in the construction of political belief, in turn, alter perceptions of the moral responsibility of endorsing specific political beliefs. Relatedly, future work might also explore whether different components of political beliefs (e.g., support for policies; support for candidates) are perceived as more intentional than others. Third, the present study made use of a convenience sample conducted on Amazon Mechanical Turk. While previous work suggests that the use of online convenience samples can recover valid treatment effect estimates (Mullinix et al. 2015; Coppock 2019), future work could replicate the present findings using a more nationally-representative sample. Finally, although my results suggest that depolarization interventions which exclusively emphasize the biological science of ideological belief alone are not likely to engender sweeping depolarizing effects, they do suggest, perhaps hopefully, that exposure to this type of research neither increases the partisan affective gulf nor harms the likelihood of cross-party interactions. Thus, concerns about the potential negative or antisocial effects of encountering such frames, at least in the context of political belief, may be overstated.

Given that most of us reflexively think that we choose and are responsible for our own 
political beliefs, it can be admittedly troubling to confront the possibility that we may not exercise as much control over these beliefs as our intuition seems to suggest. We proudly weaponize bumper stickers and traffic in taunt-infused comment-thread witticisms in the war against the political "other", all in part because we believe that the other side chooses to believe what they believe freely and unencumbered. The root of our frustrations, of increased political violence and partisan discrimination (Lelkes and Westwood 2017), seems to hinge on this often unquestioned assumption that we exercise agency over our belief systems. However, the emergent neurobiological and genetic science of political belief suggests that this assumption is misguided and in lieu of accented partisan violence and taunting, potentially dangerous. It seems odd, albeit perhaps quintessentially human, to believe that our political beliefs are somehow completely separable from the biological and genetic programming which circumscribes all of our cognitions. However, in disavowing this belief and accepting that our own ideologies are partially the byproduct of biological and genetic processes over which we have no control, we may end up promoting a more tolerant and kinder civil society. 


\section{References}

Alford, John R., Carolyn L. Funk, and John R. Hibbing. 2005. "Are Political Orientations Genetically Transmitted?." American Political Science Review 99(2): 153-167.

Aronow, Peter M., Jonathon Baron, and Lauren Pinson. 2018. "A Note on Dropping Experimental Subjects who Fail a Manipulation Check." Political Analysis: 1-18.

Astuti, Rita, and Maurice Bloch. 2015. "The Causal Cognition of Wrong Doing: Incest, Intentionality, and Morality." Frontiers in Psychology 6 (136) 1-7.

Baumeister, Roy F., E. J. Masicampo, and C. Nathan DeWall. 2009. "Prosocial Benefits of Feeling Free: Disbelief in Free Will Increases Aggression and Reduces Helpfulness." Personality and Social Psychology Bulletin 35(2): 260-268.

Baumeister, Roy F., and Lauren E. Brewer. 2012. "Believing versus Disbelieving in Free Will: Correlates and Consequences." Social and Personality Psychology Compass 6(10): 736-745.

Condit, Celeste M., Roxanne L. Parrott, and Tina Harris. 2006. "Laypeople and Behavioral Genetics." In Erik Parens, Audrey R. Chapman, and Nancy Press, eds., Wrestling with Behavioral Genetics. Baltimore: Johns Hopkins University Press, 286-309.

Coppock, Alexander. 2019. "Generalizing From Survey Experiments Conducted on Mechanical Turk: A Replication Approach." Political Science Research and Methods 7(3): 613-628.

Cushman, Fiery. 2008. "Crime and Punishment: Distinguishing the Roles of Causal and Intentional Analyses in Moral Judgment." Cognition, 108(2): 353-380.

Cushman, Fiery, et al. 2013. "The Development of Intent-Based Moral Judgment." Cognition 127(1): 6-21.

Dawes, Christopher T., and James H. Fowler. 2009. "Partisanship, Voting, and the Dopamine D2 Receptor Gene." The Journal of Politics 71(3): 1157-1171.

Downs, Anthony. 1957. "An Economic Theory of Democracy.": 260-276.

Dweck, Carol S. 2008. Mindset: The New Psychology of Success. Random House Digital, Inc.

Gaines, Brian J., and James H. Kuklinski. 2011. "Experimental Estimation of Heterogeneous Treatment Effects Related to Self-Selection." American Journal of Political Science 55(3): 724-736.

Glenn, A. L., Raine, A., Laufer, W. S. 2011. "Is It Wrong to Criminalize and Punish Psychopaths?" Emotion Review 3: 302-304.

Greene, Joshua, and Jonathan Haidt. 2002. "How (and Where) Does Moral Judgment Work?." Trends in Cognitive Sciences 6(12): 517-523. 
Haslam, Nick, and Jennifer Whelan. 2008. "Human Natures: Psychological Essentialism in Thinking About Differences Between People." Social and Personality Psychology Compass 2(3): 1297-1312.

Hatemi, Peter, and Rose McDermott. 2012. "The Political Psychology of Biology, Genetics, and Behavior." Political Psychology 33(3): 307-312.

Hatemi, Peter, et al. 2014. "Genetic Influences on Political Ideologies: Twin Analyses of 19 Measures of Political Ideologies from Five Democracies and Genome-Wide Findings from Three Populations." Behavior Genetics 44(3): 282-294.

Imai, Kosuke, Luke Keele, and Teppei Yamamoto. 2010. "Identification, Inference and Sensitivity Analysis for Causal Mediation Effects." Statistical Science: 51-71.

Iyengar, Shanto, Gaurav Sood, and Yphtach Lelkes. 2012. "Affect, Not Ideology: A Social Identity Perspective on Polarization." Public Opinion Quarterly 76(3): 405-431.

Kalmoe, Nathan, and Mason, Lilliana. 2018. "Lethal Mass Partisanship: Prevalence, Correlates, and Electoral Contingencies." Paper presented at the 2018 American Political Science Association's Annual Meeting, Boston, MA, Aug. 30 - Sept. 2.

Kanai, Ryota, et al. 2011. "Political Orientations Are Correlated with Brain Structure in Young Adults." Current Biology21(8): 677-680.

Lelkes, Yphtach, and Sean J. Westwood. 2017. "The Limits of Partisan Prejudice." The Journal of Politics 79(2): 485-501.

Levy, N. 2005. "The Good, The Bad, and The Blameworthy." Journal of Ethics and Social Philosophy 1(2): 1-16.

Nam, H. Hannah, et al. 2018. "Amygdala Structure and The Tendency to Regard the Social System as Legitimate and Desirable." Nature Human Behaviour 2(2): 133-138.

MacKenzie, Michael J., Kathleen D. Vohs, and Roy F. Baumeister. 2014. "You Didn't Have to Do That: Belief in Free Will Promotes Gratitude." Personality and Social Psychology Bulletin 40(11): 1423-1434.

Mullinix, Kevin J., et al. 2015. "The Generalizability of Survey Experiments." Journal of Experimental Political Science 2(2): 109-138.

Nahmias, Eddy, et al. 2005. "Surveying Freedom: Folk Intuitions about Free Will and Moral Responsibility." Philosophical Psychology 18(5): 561-584.

Nichols, S. 2006. "Folk Intuitions on Free Will." Journal of Cognition and Culture 6: $57-86$.

Oxley, Douglas R., et al. 2008. "Political Attitudes Vary with Physiological Traits." Science 321(5896): 1667-1670.

Pereboom, Derk. 2009. Free Will Skepticism and Prevention of Crime. Cambridge: Cambridge University Press. 
Rucker, Derek D., et al. 2011. "Mediation Analysis in Social Psychology: Current Practices and New Recommendations." Social and Personality Psychology Compass 5(6): 359371.

Schneider, Stephen P., Kevin B. Smith, and John R. Hibbing. 2018. "Genetic Attributions: Sign of Intolerance or Acceptance?." The Journal of Politics 80(3): 1023-1027.

Settle, Jaime E., Christopher T. Dawes, and James H. Fowler. 2009. "The Heritability of Partisan Attachment." Political Research Quarterly 62(3): 601-613.

Shariff, Azim F., et al. 2012. "Diminished Belief in Free Will Increase Forgiveness and Reduces Retributive Punishment." Manuscript under review.

Stix, Gary. 2015. "Site Survey Shows 60 Percent Think Free Will Exists. Read Why." Scientific American. 12 Aug. 2019 https://blogs.scientificamerican.com/talking-back/ site-survey-shows-60-percent-think-free-will-exists-read-why/.

Tingley, Dustin, et al. "Mediation: R Package for Causal Mediation Analysis." Journal of Statistical Software 59:5.

Tritt, Shona M., et al. 2016. "Ideological Reactivity: Political Conservatism and Brain Responsivity to Emotional and Neutral Stimuli." Emotion 16(8): 1172-1185.

Umbach, Rebecca, Colleen M. Berryessa, and Adrian Raine. 2015. "Brain Imaging Research on Psychopathy: Implications for Punishment, Prediction, and Treatment in Youth and Adults." Journal of Criminal Justice 43(4): 295-306.

Vohs, Kathleen D., and Jonathan W. Schooler. 2008. "The Value of Believing in Free Will: Encouraging a Belief in Determinism Increases Cheating." Psychological Science 19(1): 49-54.

Willoughby, Emily A., et al. 2019. "Free Will, Determinism, and Intuitive Judgments about the Heritability of Behavior." Behavior Genetics 49(2): 136-153.

Yang, Andrew. 2019. "According to twins studies between one-third and one-half of political alignment is linked to genetics; that is most of us are born somewhat wired to be liberal or conservative. If this is the case we need to build bridges as much as possible. It's not just info or culture." June 1, 2019, 10:40 A.M. Tweet.

Young LL, Saxe R. 2009. "Innocent Intentions: A Correlation Between Forgiveness for Accidental Harm and Neural Activity." Neuropsychologia 47(10): 2065-2072. 


\section{Appendix}

\section{Appendix A: Manipulation Text}

Treatment Condition

Nature and Your Politics

By: Elisa Jackie

July 20, 2019

When most of us think about how we came to our political views, we often give a straightforward answer. We believe our stances on taxes, immigration, or national security are largely a matter of our own choice. We assume our life experiences are the root of our political ideologies and that we arrive at our ideologies by carefully and rationally weighing the pros and cons of different policy positions. But what if there is something deeper in us that drives our political beliefs?

In recent years, political scientists have started to understand and study how our political views may also be influenced by our biology. Studies, for instance, have found that the size and degree of activation of particular brain regions (e.g., the amygdala) as well as particular genetic biomarkers (e.g., the A2 allele of the D2 dopamine receptor gene) can predict with high degrees of accuracy whether we adopt more liberal or conservative positions on policies and whether we identify with a political party even after statistically controlling for environmental factors. A number of twin-studies have also found evidence that approximately $40-50 \%$ of the variation in ideological beliefs is heritable which can explain why parental ideology tends to correlate strongly with the ideology of their children when they grow up. This research demonstrates that a substantial proportion of the variation in our political attitudes and beliefs can be explained by our genetics and other aspects of our neurophysiology and hard-wiring.

These emergent research findings suggest that a lot of how we perceive the world and how others perceive the world - including those we may disagree with strongly on hot button political questions - is, in some sense, not a matter of our own choosing. It is not as though we can control or choose our genes or the wiring of our brains.

\section{Control Condition}

\section{Sloths}

By: Elisa Jackie

July 20, 2019

Sloths live in the tropical forests of Central and South America. With their long arms and shaggy fur, they resemble monkeys, but they are actually related to armadillos and anteaters. They can be 2 to 2.5 feet (0.6 to 0.8 meters) long and, depending on species, weigh from 8 to 17 pounds (3.6 to 7.7 kilograms). 
There are two main species of sloth, identified by whether they have two or three claws on their front feet. The two species are quite similar in appearance, with roundish heads and stubby tails. Two-toed sloths are slightly bigger and tend to spend more time hanging upsidedown than their three-toed cousins, who will often sit upright in the fork of a tree branch. Three-toed sloths have facial coloring that makes them look like they're always smiling. They also have two extra neck vertebrae that allow them to turn their heads almost all the way around. 


\section{Appendix B: Summary Statistics}

Table 4: Summary Statistics

\begin{tabular}{lccccccc}
\hline \hline Statistic & $\mathrm{N}$ & Mean & St. Dev. & Min & Pctl(25) & Pctl(75) & Max \\
\hline Age & 486 & 37.0 & 11.5 & 18 & 29 & 43.8 & 70 \\
Sex: Male & 485 & 0.5 & 0.5 & 0.0 & 0.0 & 1.0 & 1.0 \\
Race: White & 485 & 0.7 & 0.5 & 0.0 & 0.0 & 1.0 & 1.0 \\
Education & 485 & 4.4 & 1.4 & 1.0 & 3.0 & 5.0 & 8.0 \\
Religiosity & 481 & 2.5 & 1.4 & 1.0 & 1.0 & 4.0 & 5.0 \\
Party Identification & 486 & 4.5 & 2.2 & 1 & 3 & 7 & 7 \\
Ideology & 485 & 3.7 & 1.8 & 1.0 & 2.0 & 5.0 & 7.0 \\
Subjective SES & 485 & 1.6 & 0.9 & 0.0 & 1.0 & 2.0 & 4.0 \\
Income & 485 & 2.6 & 1.7 & 0.0 & 1.0 & 4.0 & 7.0 \\
Employment Status & 479 & 0.9 & 1.0 & 0.0 & 1.0 & 1.0 & 10.0 \\
Political Knowledge & 485 & 1.1 & 0.8 & 0.0 & 0.0 & 2.0 & 2.0 \\
Political Interest & 485 & 2.6 & 1.1 & 0.0 & 2.0 & 3.0 & 4.0 \\
Trust in Science & 486 & 4.6 & 0.9 & 1 & 4 & 5 & 5 \\
\hline
\end{tabular}




\section{Appendix C: Covariate Balance Results}

I assess covariate balance through use of a logistic regression model in which treatment assignment is the dependent variable. I use the control condition as the base condition. No variables achieve statistical significance at conventional levels, suggesting that randomization worked as intended.

Table 5: Covariate Balance Check

\begin{tabular}{lr}
\hline \hline & Dependent Variable: \\
\cline { 2 - 2 } & Treatment Assignment \\
\hline Age & $0.008(0.009)$ \\
Sex: Male & $-0.112(0.194)$ \\
Race: White & $0.036(0.210)$ \\
Education & $-0.036(0.072)$ \\
Religiosity & $-0.030(0.075)$ \\
Party Identification & $-0.003(0.064)$ \\
Ideology & $-0.056(0.082)$ \\
Subjective SES & $0.015(0.148)$ \\
Income & $0.028(0.074)$ \\
Employed & $0.031(0.096)$ \\
Political Knowledge & $-0.152(0.131)$ \\
Political Interest & $-0.018(0.088)$ \\
Constant & $0.316(0.536)$ \\
\hline Observations & 475 \\
Log Likelihood & -326.845 \\
\hline \hline Note: & $* \mathrm{p}<0.1 ;{ }^{* *} \mathrm{p}<0.05 ;{ }^{* * *} \mathrm{p}<0.01$
\end{tabular}




\section{Appendix D: Question Text and Coding}

Table 6: Question and Variable Descriptions

\section{Variable Name}

Age

Sex

Social Distance

Trait Attributions

Feeling Thermometer

\section{Description}

What is your age in years?

Which gender do you identify with?

How do you think you would react if a member of your immediate family told you they were going to marry: (A Democrat/A Republican/A Liberal/A Conservative)

For each of the following traits (political ideology; height; party affiliation; intelligence; criminality), please indicate the extent to which you think the trait is determined by genetic and biological factors, environmental factors, and personal choice. The total for each row should add up to $100 \%$.

We would now like to get your feelings toward some groups who are in the news these days. We'll show the name of a person or group and we'd like you to rate that person or group using something we call the feeling thermometer. Ratings between 50 degrees and 100 degrees mean that you feel favorable and warm toward the person. Ratings between 0 degrees and 50 degrees mean that you don't feel favorable toward the person and that you don't care too much for that person or group. You would rate the person at the 50-degree mark if you don't feel particularly warm or cold toward the person. If you come to a person whose name you don't recognize, you don't need to rate that person. Just click Next and we'll move on to the next one. (Republicans/Democrats/Independents)

\section{Coding}

18-99

Non-Male $=0 ;$ Male $=1$

Unhappy $=0 ;$ Wouldn't Matter $=1 ;$ Happy $=2$

$0-100$ 


\section{General Compromise}

Specific Compromise

\section{Viewpoint Diversity}

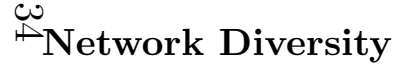

\section{Income}

Subjective Class

Education

\section{Religiosity \\ Race: White \\ Employment Status \\ Science Trust \\ Political Interest}

\section{Political Knowledge Q1}

Political Knowledge Q2
Which statement comes closer to your view even if neither is exactly right? I like elected officials who: [Make compromises with people they disagree with; Stick to their positions]

Think about how Republican and Democratic leaders in Congress should address the most important issues facing the country. Imagine a scale from zero to 100 where 100 means Democratic leaders get everything they want and Republican leaders get nothing they want, and zero means Republican leaders gets everything they want and Democratic leaders get nothing they want. Where on this scale from zero to 100 do you think they should end up? (Republican leaders/Democrat leaders)

How important is it to you to seek out a variety of perspectives when thinking about political issues?

How important is it to you to seek out ideologically-diverse discussion partners?

What is your annual household income?

What is your current socioeconomic status?

What is the highest level of education you have received?

How important is religion in your life?

What racial or ethnic group best describes you? Are you currently employed?

How much would you say you trust scientists?

How interested are you in information about what's going on in government and politics?

For how many years is a United States Senator elected?

On which of the following does the U.S. federal government currently spend the least?
$0=$ Stick to positions; $1=$ Compromise

$1=$ Very Unimportant; $7=$ Very Important

$1=$ Very Unimportant; $7=$ Very Important

$0=$ Less than $\$ 20,000 ; 7=$ Over $\$ 200,000$

$0=$ Lower class; $4=$ Upper class

$0=$ Less than a HS diploma; $8=$ Doctorate (e.g. PhD, EdD)

$0=$ Not at all important; $5=$ Extremely Important

$0=$ Nonwhite $1=$ White

$0=$ Unemployed; $1=$ Employed

$0=$ Never; $5=$ Always

$0=$ Not interested at all; $5=$ Extremely interested

$0=2$ years, 4 years, 8 years; $1=6$ years

$0=$ Medicare, National Defense, or Social Security; $1=$ Foreign Aid 


\section{Ideology}

Party Identification - 3 Point

Party Identification - 7 Point

ci
We hear a lot of talk these days about liberals and conservatives. Here is a seven-point scale on which the political views that people might hold are arranged from extremely liberal to extremely conservative. Where would you place yourself on this scale?

Generally speaking, do you usually think of yourself as a Republican, a Democrat, or as an Independent?

Would you call yourself a strong Republican or a not very strong Republican? Do you think of yourself as closer to the Republican or Democratic party?
$1=$ Very Liberal; $7=$ Very Conservative

$0=$ Democrat; $1=$ Independent; $2=$ Republican $1=$ Strong Democrat; $7=$ Strong Republican 